\title{
Herbivory and fire interact to affect forest understory habitat, but not its use by small vertebrates
}

C. N. Foster ${ }^{*}$, P. S. Barton ${ }^{a}$, C. F. Sato ${ }^{a, b}$, J. T. Wood ${ }^{a}$, C.I. MacGregor ${ }^{a, b}$ and D. B. Lindenmayer a,b,c

${ }^{a}$ Fenner School of Environment and Society, The Australian National University, Canberra ACT 0200, Australia.

${ }^{\mathrm{b}}$ Australian Research Council Centre of Excellence for Environmental Decisions and the National Environmental Research Program Environmental Decisions Hub, The Australian National University, Canberra ACT 0200, Australia.

${ }^{\mathrm{c}}$ The Long-term Ecological Research Network, The Australian National University, Canberra ACT 0200, Australia.

"Corresponding author: claire.foster@anu.edu.au

Short title: Fire-herbivory interactions drive vegetation but not fauna

Words: 3962 


\section{$1 \quad$ Abstract}

2 Herbivory and fire are two disturbances which often co-occur, but studies of their interactive

3 effects are rare outside of grassland ecosystems. We experimentally tested the interactive

4 effects of prescribed fire and macropod herbivory on forest understory vegetation and its

5 vertebrate fauna. Fire and herbivory interacted synergistically to affect forest understory

6 vegetation, with palatable plants showing poor post-fire recovery in un-fenced sites compared

7 with herbivore exclusion sites. Despite this strong interactive effect on vegetation, small

8 vertebrates responded to the individual, and not the interactive effects of disturbance. The

9 native insectivorous mammal Antechinus stuartii was more frequently encountered on large

10 herbivore exclusion sites, as was the introduced European rabbit. In contrast, the small skink

11 Lampropholis delicata was more common on sites with high densities of large herbivores.

12 Skinks, snakes and European rabbits were also more active on burnt than unburnt sites. Our

13 results suggest that it may be necessary to manage the macropod herbivore population after

14 fire to prevent the decline of palatable plants, and maintain the dense habitat required by

15 some small mammals. However, as the invasive rabbit was most active in macropod-free

16 sites after fire, any management must include control of both types of herbivores. A mix of

17 understory densities may also need to be maintained to ensure the persistence of species

18 preferring more open habitats. Our study demonstrates that interactive effects of disturbance

19 on vegetation communities may not lead to predictable effects on animals, and highlights the

20 importance of considering both multiple stressors, and multiple species, in the management

21 of disturbance regimes.

\section{Keywords}

23 Disturbance interaction, browsing, grazing, indirect effects, kangaroo, synergistic effects 
25 Disturbance regimes play a central role in ecosystem dynamics (Willig and Walker, 1999).

26 However, in many parts of the world, natural disturbance regimes have been disrupted, with

27 unwanted outcomes for biodiversity (Hobbs and Huenneke, 1992, Sinclair and Byrom, 2006).

28 Thus, many biodiversity conservation programs aim to reinstate natural disturbance regimes

29 (Fuhlendorf et al., 2010, Noss et al., 2006), but achieving this in systems where multiple

30 disturbances co-occur may be difficult. Co-occurring disturbances can interact to produce

31 distinctly different outcomes from what would be expected based on individual effects

32 (Didham et al., 2007, Tylianakis et al., 2008) and a poor understanding of these interactions

33 can lead to unexpected and undesirable management outcomes (Lindenmayer et al., 2010,

34 Tylianakis et al., 2008).

The importance of disturbance interactions for structuring grasslands and heathlands has been widely recognised, and re-establishing fire-grazing interactions is identified as a priority for maintaining biodiversity in these habitats (Fuhlendorf et al., 2010, Van Langevelde et al., 2003). However, understanding of how fire and herbivory interact to affect species in forested habitats remains limited (Foster, Barton and Lindenmayer, 2014, Royo et al., 2010,

41 Wisdom et al., 2006). As the interactive effects of fire and herbivory depend on the scale, intensity and timing of these disturbances, the outcome of interactions can be highly variable (Fuhlendorf et al., 2010, Wisdom et al., 2006). For example, at a local-scale, deer browsing after fire supressed dominant shrub species, increasing herbaceous plant richness in a forest understory (Royo et al., 2010). Conversely, heavy macropod herbivory following fire limited grass and forb recovery (Tuft, Crowther and McArthur, 2012). At a larger scale, Bailey and Whitham (2002) found that elk (Cervus canadensis) browsed more heavily in areas of aspen 
heavy browsing reversed the positive effect of browsing on arthropod richness that occurred after moderate intensity fire. While such studies indicate that fire-herbivory interactions are likely to be prevalent in forested ecosystems (Royo and Carson, 2006), investigations of animal responses to the combined effects of these disturbances remain rare (Foster et al., 2014, Wisdom et al., 2006).

54

We combined prescribed fire and large herbivore exclusion treatments to test the interactive effects of fire and herbivory on understory vegetation and small vertebrates in a temperate forest ecosystem. As the management of disturbances is often targeted at plants, with the assumption that this will also cater for the needs of animals (Clarke, 2008), it is important to understand whether such assumptions are valid, and whether fauna respond in a predicable way to disturbances. Our study addressed the following questions: (1) How do fire, herbivory and their interaction affect understory habitat structure at the site level? (2) How do these disturbances affect site occupancy by small vertebrate fauna? We expected that vertebrate species would respond differently to the experimental treatments due to differences in their habitat and dietary preferences, and that these responses would be mediated by changes in vegetation structure. For example, we expected that both fire and herbivory would reduce understory cover, and lead to negative effects on site occupancy by vertebrates preferring dense understory habitats (Table 1). We provide recommendations for biodiversity conservation based on our findings.

\section{Materials and methods}

\section{Study site}

We conducted our study in Booderee National Park (BNP); a $\sim 6500$ ha peninsula in southeastern Australia $\left(35^{\circ} 10^{\prime} \mathrm{S}, 150^{\circ} 40^{\prime} \mathrm{E}\right)$. We established sites within Eucalyptus pilularis forest, which is the most widespread vegetation type in BNP (Taws, 1998). An intensive fox (Vulpes 
vulpes) baiting program has been conducted in BNP since 1999 to protect native species from predation (Dexter et al., 2012). Over the last decade, there has been a tenfold increase in native herbivores in BNP (predominantly swamp wallaby, Wallabia bicolor, and eastern grey kangaroo, Macropus giganteus), which is attributed to reduced predation by foxes (Lindenmayer et al., 2014). Small-scale exclosure trials indicate that this high abundance of herbivores could be driving changes in vegetation composition (Dexter et al., 2013), and there is concern about flow-on effects for smaller vertebrates, which include a number of threatened species (Dexter et al., 2012). As fire is a naturally occurring disturbance within BNP, occurring both as wildfire and low-intensity prescribed burning (Lindenmayer et al., 2008), it is important to understand how native herbivores interact with fire regimes.

\section{Study design}

We quantified the interactive effects of fire and herbivory on vegetation and small vertebrates using a randomised blocked experiment. We combined three levels of large herbivore exclosure and two levels of burning treatment in a factorial design (Appendix 1). We replicated each treatment combination across four blocks to give 24 sites. For the exclosure treatments, we excluded macropod herbivores from $25 \times 25 \mathrm{~m}$ sites, using $1.1 \mathrm{~m}$ tall wire fencing, in June 2012. We created three levels of herbivore exclosure treatment: high activity (open treatment - no fence), intermediate activity (partial treatment - sites were fenced but gates opened and closed at two month intervals to simulate lower herbivore pressure), and no large herbivores (exclosure treatment). For the burnt treatments, we conducted $50 \times 50 \mathrm{~m}$ burns in August 2012, with the 25 × 25 m site in the centre of the burnt area. Fire was lowintensity, removing approximately $95 \%$ of understory vegetation and did not reach the canopy (scorch height $1.5-4 \mathrm{~m}$ ) or burn large logs. 


\section{Data collection}

100 We surveyed understorey vegetation prior to treatment in April/May 2012 and repeated

101 surveys biannually until May 2014. We sampled four $3 \times 3 \mathrm{~m}$ quadrats in each site, with each

102 quadrat at least $1.5 \mathrm{~m}$ from the fence. We recorded four vegetation variables, representing

103 important attributes of fauna habitat; total understorey projective cover (\%), projective cover

104 of bracken (Pteridium escelentum) (\%), understorey height (averaged across 10 locations per quadrat using the stick-and-disc method of Smit et al. (2001); disc $100 \mathrm{~mm}$ diameter, $4.7 \mathrm{~g}$ weight) and litter depth (averaged across10 locations per quadrat).

We surveyed macropod herbivore activity by counting scats along two $25 \times 2 \mathrm{~m}$ transects

$109\left(100 \mathrm{~m}^{-2}\right)$ per site, summing counts to give one count per site. As macropods defecate more while feeding than resting (Johnson, Jarman and Southwell, 1987), pellet counts can give a

111 comparative measure of macropod feeding pressure between sites (Howland et al., 2014). We

112 surveyed transects every two months from August 2012 to May 2014, removing scats after

113 each survey to avoid re-counting. We also monitored European rabbit (Oryctolagus

114 cuniculus) activity using these transects, counting the number of rabbit diggings every two months from June 2013 to May 2014.

117 We surveyed site use by small mammals through live trapping in April/May 2012 and then

118 every six months until May 2014. For each survey, we set eight Elliott traps per site for four

119 consecutive nights. We ear marked animals with a permanent marker to identify recaptures

120 within a survey.

122 We monitored reptiles using iron sheeting as artificial substrates. We set out four $1 \times 1 \mathrm{~m}$

123 sheets per site in July 2012, and checked them on two consecutive mornings approximately 124 every two months from October 2012 to May 2014. To minimise biases due to time of day, 
125 we rotated the order of site checking so that each site had one early morning and one late morning check per sampling period. To avoid non-independence of counts within a survey,

127 we used the maximum value of the two consecutive counts for each species. Weather

128 conditions meant that some surveys returned few individuals. Therefore, for data analysis, we 129 excluded surveys with fewer than three detections for that species.

131 To measure arthropod prey availability, we sampled ground-dwelling beetles and spiders 132 using pitfall traps, counting the total captures per trap. We deployed four $250 \mathrm{ml}(100 \mathrm{~mm}$ 133 diameter) traps per site (2/3 filled with non-toxic polyethylene glycol solution) for two weeks 134 in November 2012 and 2013.

\section{Data analysis}

137 To assess how fire-herbivory interactions affected habitat structure (question 1), and fauna

138 occupancy (question 2) we tested treatment effects on dependent variables using linear

139 mixed models (LMMs) for vegetation variables and generalised linear mixed models

140 (GLMMs) with Poisson errors for animal counts. Vegetation variables were understory cover

$141(\%)$, understory cover excluding bracken (\%, total understory cover minus cover of bracken),

142 understory height $(\mathrm{m})$, and leaf litter depth $(\mathrm{mm})$. We analysed understory cover excluding

143 bracken because bracken is a dominant, unpalatable species which could mask responses of

144 other plants. Bracken also provides little of the ground-level structure important for small

145 vertebrates (Bennett, 1993). Animal count variables were macropod scats, rabbit diggings,

146 antechinus captures, delicate skink (Lampropholis delicata) and eastern small-eyed snake

147 sightings (Cryptophis nigrescens), and spider and beetle captures.

149 We fitted each dependent variable with the full fixed effects model of

150 herbivores*burning*time, and random effects of block/site/quadrat for vegetation and 
151 block/site for animal variables to account for the repeated measures. A first-order auto-

152 regressive covariance structure on the random effects was trialled for the vegetation LMMs

153 but was not used as it did not improve model fit ( $\triangle \mathrm{AIC}<2$, Pinheiro and Bates, 2000). We

154 did not define a covariance structure for animal responses as inspection of residuals indicated

155 little evidence of temporal autocorrelation, and methods for fitting such structures with

156 GLMMs are not well developed (Zuur et al., 2009). We used Akaike information criterion,

157 corrected for small sample size (AICc), to select the most parsimonious model from all

158 possible subsets of the full model (19 models) (Burnham and Anderson, 2002). If models

159 within two AICc of the top ranked model included predictors not included in the top model,

160 we also discussed these alternate models. We excluded pre-treatment surveys from analyses

161 to avoid spurious time $\times$ treatment interactions.

162

163 The properties of some animal variables meant that adjustments to the full model were

164 necessary. Specifically, to adjust for over-dispersion of macropod scat data $(\varphi=6.9)$, rabbit

165 digging data $(\varphi=2.7)$ and arthropod data $(\varphi=3.1)$, we added an observation-level random

166 effect to the models for these variables (Harrison, 2014). Further, for the macropod model,

167 we divided the partial herbivore treatment into two categories: partial - open months, and

168 partial - closed months, to better describe this treatment. As there were low numbers of

169 macropod scats in exclosure and partial - closed month treatments, they were excluded from

170 this analysis. For the GLMM of antechinus captures, we ran model selection on all subsets of

171 the full model of herbivores*burning*time, plus an alternate model with 'season' substituted

172 for 'time' (giving 33 different models for comparison). This accounted for the strong seasonal

173 variation in antechinus abundance (Lazenby-Cohen and Cockburn, 1991). Finally, as low

174 mean counts for the two reptile species meant some models including the burn.time fixed

175 effect did not converge, we excluded five models for the delicate skink and three models for

176 the small-eyed snake from model comparisons. LMMs were performed using the lme 
177 function in the package MASS, GLMMs using the glmer function in the package lme4 and

178 AICc model ranking using the package AICcmodavg, within R version 3.0.1 (R Core Team, 179 2013).

\section{$180 \quad$ Results}

\section{$181 \quad$ Vegetation structure}

182 Vegetation structure responded both to the burning and herbivore exclosure treatments, as 183 well as their interaction (Table 2). Understory vegetation cover at unburnt sites declined in

184 open and partial treatments over time, but remained stable in exclosure sites (Fig. 1a). After 185 an initial reduction after fire, a similar decline was observed for burnt, open sites. However, burnt partial and exclosure sites remained stable. (Fig. 1a, Appendix 2). When bracken was excluded from understory cover, there was a strong exclosure $\times$ time interaction, as cover on open and partial exclosure sites declined or remained low, while on full exclosure sites cover increased through time (Fig. 1b, Appendix 2). The burning $\times$ time interaction was also

190 important, as non-bracken vegetation increased over time on all burnt sites. Compared with other treatments, burnt, open sites had a high proportion of bracken, with very little nonbracken vegetation present across all time periods (Fig. 1b). Both understory height and leaf litter depth responded to the burning $\times$ time interaction, but not to any other interaction terms

194 (Table 2). Understory height was reduced by fire but had recovered after 21 months (Fig. 2a).

195 Litter depth recovered more slowly, remaining lower in burnt than unburnt sites across all 196 time periods (Fig. 2b). The second ranked model for understory height also included an exclosure main effect, where vegetation was slightly taller on exclosure than on open sites

198 (Appendix 2). 
201 Exclosure treatments successfully excluded macropod herbivores, with very low scat counts

202 in exclosure treatments (Error! Bookmark not defined. $\bar{x}=0.71 \pm 0.52$ ). When partial

203 treatment gates were open, scat counts were 56\% lower in partial than in open treatments

204 (Fig. 3a). Macropods also responded to burning, showing higher activity in burnt than unburnt sites (Table 2, Fig 3). There were three competing models for rabbit diggings, with models including time, time plus exclosure and time plus burning all explaining similar levels

207 of variation in the data (Table 2). Rabbit activity peaked in summer and tended to be higher 208 in sites without macropods (partial and full exclosure treatments) and in burnt sites (Fig. 4, 209 Appendix 2).

211 Brown antechinus captures were highest in herbivore exclusion sites, and in Autumn (May)

212 surveys (Table 2, Fig. 5). The second ranked model also included burning as a fixed effect

213 (Table 2), where antechinus captures were slightly lower in burnt than unburnt sites

214 (Appendix 2). Both the delicate skink and the eastern small-eyed snake were encountered more frequently in burnt sites than unburnt sites (Table 2, Fig. 6, Appendix 2). Delicate skink numbers also tended to be higher in open and partial than in full exclosure sites and were

217 higher in the first survey (three months post-fire), than at any other time (Table 3, Fig, 6).

218 Beetles and spiders captures were 65\% higher in the first year (2012, Error! Bookmark not

219 defined. $\bar{x}=31.3 \pm 3.1)$ than the second $(2013, \bar{x}=18.9 \pm 1.96)$, and the second ranked model indicated that captures were also slightly higher in burnt than in unburnt sites (Table 2, Appendix 2).

\section{Discussion}

223 Fire and herbivory can interact strongly in space and time to shape the structure of vegetation communities (Koerner and Collins, 2014, Royo and Carson, 2006, Van Langevelde et al., 
2003). However, animal responses to the fire $\times$ herbivory interaction are rarely studied (but see Fuhlendorf et al., 2010, Kimuyu et al., 2014, Kutt and Woinarski, 2007). In our experimental test of the interactive effects of fire and large herbivores, we found that forest understory structure responded to the fire $\times$ herbivore exclosure interaction, but vertebrate site occupancy was affected only by the individual effects of disturbance. This suggests that local changes in vegetation structure may not be an adequate predictor of animal responses to disturbance and that animals warrant individual consideration for the management of ecosystems that are subject to both recurring fire and herbivory.

\section{Question 1: Changes to habitat structure}

235 As expected, fire and herbivory both affected habitat structure, and effects differed with disturbance type. The limited recovery of non-bracken vegetation on burnt sites with high densities of large herbivores (Fig. 1), was consistent with previous studies (Meers and Adams, 2003, Tuft et al., 2012). Both of these previous studies attributed the stronger effect of herbivory on burnt sites to greater herbivore pressure, driven by the attraction of herbivores to the fresh plant growth following fire. This is a commonly reported mechanism explaining fire $\times$ herbivore interactions (Klop, van Goethem and de Iongh, 2007), for which we also found evidence, as indicated by macropod activity being greatest on recently burnt sites (Fig. 2b).

In contrast to the non-bracken vegetation, bracken recovered well in burnt, open sites, and made up a large proportion of the vegetation in these sites (Fig. 1). Bracken can regenerate rapidly following fire and suppress other plants. However, after an initial post-fire pulse, bracken cover usually declines over time, as other plants become dominant (Tolhurst and Turvey, 1992). Our results indicate that abundant macropod herbivores may be disrupting this successional process by selectively feeding on more palatable vegetation, maintaining the 
bracken-dominated understory. As prescribed fire is commonly used in this system to reduce forest fuel loads and promote vegetation heterogeneity and floristic diversity (Morrison et al., 1996), our results suggest that herbivore management following fire may be important to maintain a heterogeneous forest flora.

\section{Question 2: Habitat use by vertebrates}

Despite the strong effect of the fire $\times$ herbivory interaction on vegetation, habitat use by

vertebrates was affected only by the individual effects of disturbances and not their interaction. The increased rabbit activity we observed on herbivore exclusion and recently burnt sites was consistent with previous studies of small herbivore responses to large herbivore removal (Keesing, 1998) and fire (Leigh et al., 1987, Moreno and Villafuerte, 1995). Competitive release of small herbivores following a reduction in large herbivore densities can result in increased herbivory by small herbivores, with subsequent impacts on vegetation communities (Lagendijk, Page and Slotow, 2012). Our results suggest that control of native macropod herbivores may favour introduced rabbits, particularly after fire when fresh plant growth is abundant. Therefore, management of the native herbivore population should carefully consider the potential for competitive release of the European rabbit, which is a destructive pest species in Australia (Davey et al., 2006).

Antechinus responded positively to large herbivore exclusion, with more individuals captured in sites without macropod herbivores, regardless of burning treatment. Despite the small size of our exclosures, this response likely indicates a preference for herbivore exclusion areas, as antechinus have small foraging ranges (approximately 0.4 ha for females and 0.9 ha for males, Lazenby-Cohen and Cockburn, 1991). Further, our result is consistent with Pedersen et al. (2014), who found that antechinus captures were negatively correlated with wallaby density. The preference of antechinus for sites without large herbivores may have been due 
to the dense understory cover in exclosure sites (Bennett, 1993, Knight and Fox, 2000), providing increased foraging habitat (antechinus are scansorial) and/or greater protection from predators (e.g. Stokes et al., 2004). Other studies have found that some small mammal

280 species prefer habitats with lower densities of large herbivores (Bush et al., 2012, Keesing, 281 1998, Kutt and Gordon, 2012), but our study is the first to experimentally demonstrate this response to macropod herbivores.

284 Contrary to other studies from south-eastern Australia (Fox, 1982, Lindenmayer et al., 2008), we found only weak support for a negative response of antechinus to fire. This was likely due to the low intensity, small-scale fires used in our study. The availability of arthropod prey

287 (Table 2, Appendix 2), combined with the persistence of logs and the proximity of unburnt vegetation to burnt areas in our study, may have sufficiently maintained habitat quality for antechinus. It is likely that antechinus may have responded more strongly to a larger-scale, or higher intensity burn (Lindenmayer et al., 2008, Penn et al., 2003).

292 Delicate skinks were more common in open than in herbivore exclusion sites, and both 293 delicate skinks and small-eyed snakes were more common in burnt than unburnt sites. The negative response of delicate skins to herbivore exclusion was likely due to increased shading from recovering vegetation, which could have reduced the thermal suitability of the environment for this heliothermic species (Howard, Williamson and Mather, 2003). The

297 positive response of the delicate skink to burning was contrary to our expectation for this species, which generally recovers slowly from fire, in response to the slow accumulation of leaf litter (Taylor and Fox, 2001). Our result may therefore reflect a change in micro-habitat use following burning, rather than a change in site occupancy. Burning reduced litter depth, and in the absence of suitable leaf-litter habitat, the delicate skink may have increased its use 
302 of the artificial survey substrates for shelter, basking and foraging, as found by Croft, Reid and Hunter (2010).

305 A lack of alternative refuges also may explain the higher numbers of small-eyed snakes under

306 the artificial substrates in burnt sites. However, there are two other possible explanations for

307 this response: First is that the small-eyed snake was more common after burning as a result of 308 reduced shading of substrates, which provided warmer, more desirable diurnal refuges (Webb

309 et al., 2004). Second, the density of skinks, a key prey item for small-eyed snakes (Shine,

310 1984), may have attracted snakes to the substrates in burnt sites. Previous studies of small-

311 eyed snakes show that reduced shading after fire can improve the thermal properties of

312 diurnal refuges (Webb et al., 2005), but large wildfire can lead to population declines,

313 possibly due to increased predation (Webb and Shine, 2008). While the possible biases in our

314 reptile sampling technique mean results should be interpreted with caution, the greater

315 numbers of reptiles in burnt sites and skinks in the open treatments, indicate that maintaining

316 areas of open understory may be important for the persistence of reptiles in these forests

317 (Webb et al., 2005).

\section{Conservation implications}

320 Our results have four key implications relevant to the conservation of ecosystems subject to

321 both recurrent fire and herbivory. First, the dominance of bracken and limited recovery of

322 other vegetation in burnt, open sites indicates that short-term management of abundant macropod herbivores following prescribed fire may be useful for the conservation of structurally and floristically complex vegetation. Second, the preference of antechinus for herbivore exclusion sites suggests that management of native herbivores to promote dense understory habitat is also likely to benefit small mammals dependent on such habitats. Third,

327 the increased rabbit activity we observed on recently burnt sites, and sites without 
macropods, suggests that any plan to improve the post-fire recovery of vegetation by controlling native herbivores also should include management of rabbits. Fourth, the positive response of reptiles to the open understory of burnt sites and sites with more macropods differed from the antechinus response, and suggests that a mixed management scenario might

332 be more appropriate.

334 While our experiments were small-scale, the contrasting responses of different species to herbivory and fire indicate that a mixed management strategy promoting a heterogeneous understory may be important for the persistence of all species in our study. Heterogeneous

337 landscapes have commonly been suggested as a desired goal of land management, as such

338 landscapes are more likely to allow the co-existence of species with different niches, as well as species that require a mix of habitats (Law and Dickman, 1998, Stein, Gerstner and Kreft, 2014). In Australian landscapes, fire patch-mosaics have been recommended to promote fauna diversity, although key questions around the appropriate spatial and temporal scales of such mosaics remain unanswered (Allouche et al., 2012, Clarke, 2008, Driscoll et al., 2010).

343 While not designed to address questions of spatial scale, our study suggests that maintaining a mix of habitat types and conditions may be important for fauna in forested systems.

346 Although both fire and herbivory are often actively managed in forested systems (Gordon,

347 Hester and Festa-Bianchet, 2004, Morrison et al., 1996), these processes are usually

348 considered independently (Royo and Carson, 2006, Wisdom et al., 2006). However, the

349 interactive effects of fire and herbivory observed in our study indicate that integrating large

350 herbivore management with fire management practices is likely to be important for achieving 351 vegetation heterogeneity in forests. This could be through the fire-dependent management of

352 herbivores (e.g. controlling large herbivores across only part of a burn or after only some 353 prescribed burns), or through planning fires to consider large herbivore behaviour (e.g. 
354 reducing the edge-area ratio of prescribed burns, as macropods can be reluctant to enter open 355 areas and so feed more heavily at the edge (While and McArthur, 2006)). Our study shows

356 the value of experimental studies that quantify disturbance responses both individually and

357 collectively, and highlights the importance of considering both multiple stressors, and

358 multiple species, in the management of disturbance regimes.

\section{Acknowledgments}

360 Staff of BNP conducted prescribed burns. We thank the Department of Environment and the

361 landowners and co-managers of BNP - the Wreck Bay Aboriginal Community. The Margaret

362 Middleton Fund, The Norman Wettenhall Foundation and the Long Term Ecological

363 Research Network provided financial support. 


\section{References}

366 Allouche, O., Kalyuzhny, M., Moreno-Rueda, G., Pizarro, M. \& Kadmon, R. (2012). Areaheterogeneity tradeoff and the diversity of ecological communities. Proceedings of the National Academy of Sciences 109, 17495-17500.

Bailey, J. K. \& Whitham, T. G. (2002). Interactions among fire, aspen, and elk affect insect diversity: Reversal of a community response. Ecology 83, 1701-1712.

Bennett, A. F. (1993). Microhabitat use by the long-nosed potoroo, Potorous tridactylus, and other small mammals in remnant forest vegetation, south-western Victoria. Wildl. Res. 20, 267-285.

Bragg, J. G., Taylor, J. E. \& Fox, B. J. (2005). Distributions of lizard species across edges

Burnham, K. P. \& Anderson, D. R. (2002). Model selection and multimodel inference: a delimiting open-forest and sand-mined areas. Austral Ecol. 30, 188-200. practical information-theoretic approach. 2nd ed. edn. New York: Springer-Verlag.

Bush, E. R., Buesching, C. D., Slade, E. M. \& Macdonald, D. W. (2012). Woodland recovery after suppression of deer: cascade effects for small mammals, wood mice (Apodemus sylvaticus) and bank voles (Myodes glareolus). PLoS ONE 7, e31404.

Catling, P. \& Burt, R. (1995). Studies of the ground-dwelling mammals of eucalypt forests in south-eastern New South Wales: the effect of habitat variables on distribution and

384 Clarke, M. F. (2008). Catering for the needs of fauna in fire management: science or just wishful thinking? Wildl. Res. 35, 385-394.

386 Croft, P., Reid, N. \& Hunter, J. (2010). Experimental burning changes the quality of fallen 387 timber as habitat for vertebrate and invertebrate fauna: implications for fire management. Wildl. Res. 37, 574-581. 
Davey, C., Sinclair, A., Pech, R., Arthur, A., Krebs, C., Newsome, A., Hik, D., Molsher, R. \& Allcock, K. (2006). Do exotic vertebrates structure the biota of Australia? An experimental test in New South Wales. Ecosystems 9, 992-1008.

Davis, N. E., Coulson, G. \& Forsyth, D. M. (2008). Diets of native and introduced mammalian herbivores in shrub-encroached grassy woodland, south-eastern Australia. Wildl. Res. 35, 684-694.

Dexter, N., Hudson, M., James, S., MacGregor, C. \& Lindenmayer, D. B. (2013). Unintended consequences of invasive predator control in an Australian forest: Overabundant wallabies and vegetation change. PloS ONE 8, e69087.

Dexter, N., Ramsey, D. L., MacGregor, C. \& Lindenmayer, D. (2012). Predicting ecosystem wide impacts of wallaby management using a fuzzy cognitive map. Ecosystems 15, 1363-1379.

Didham, R. K., Tylianakis, J. M., Gemmell, N. J., Rand, T. A. \& Ewers, R. M. (2007). Interactive effects of habitat modification and species invasion on native species decline. Trends Ecol. Evol. 22, 489-496.

Driscoll, D. A., Lindenmayer, D. B., Bennett, A. F., Bode, M., Bradstock, R. A., Cary, G. J., Clarke, M. F., Dexter, N., Fensham, R., Friend, G., Gill, M., James, S., Kay, G., Keith, D. A., MacGregor, C., Russell-Smith, J., Salt, D., Watson, J. E. M., Williams, R. J. \& York, A. (2010). Fire management for biodiversity conservation: Key research questions and our capacity to answer them. Biol. Conserv. 143, 1928-1939.

Foster, C. N., Barton, P. S. \& Lindenmayer, D. B. (2014). Effects of large native herbivores on other animals. J. Appl. Ecol. 51, 929-938.

Fox, B. J. (1982). Fire and mammalian secondary succession in an Australian coastal heath. Ecology, 1332-1341. 
413 Fuhlendorf, S. D., Townsend, D. E., Elmore, R. D. \& Engle, D. M. (2010). Pyric-herbivory to

414 promote rangeland heterogeneity: Evidence from small mammal communities. Rangeland Ecol. Manage. 63, 670-678.

Gordon, I. J., Hester, A. J. \& Festa-Bianchet, M. (2004). The management of wild large herbivores to meet economic, conservation and environmental objectives. J. Appl. Ecol. 41, 1021-1031.

Harrison, X. A. (2014). Using observation-level random effects to model overdispersion in count data in ecology and evolution. PeerJ 2, e616.

Hobbs, R. J. \& Huenneke, L. F. (1992). Disturbance, diversity, and invasion: Implications for conservation. Conserv. Biol. 6, 324-337.

Howard, R., Williamson, I. \& Mather, P. (2003). Structural aspects of microhabitat selection by the skink Lampropholis delicata. J. Herpetol. 37, 613-617.

Howland, B., Stojanovic, D., Gordon, I. J., Manning, A. D., Fletcher, D. \& Lindenmayer, D. B. (2014). Eaten out of house and home: Impacts of grazing on ground-dwelling reptiles in Australian grasslands and grassy woodlands. PLOS ONE 9, e105966.

Johnson, C. N., Jarman, P. J. \& Southwell, C. J. (1987). Macropod studies at Wallaby Creek. Res. 14, 133-138.

Keesing, F. (1998). Impacts of ungulates on the demography and diversity of small mammals in central Kenya. Oecologia 116, 381-389.

Kimuyu, D. M., Sensenig, R. L., Riginos, C., Veblen, K. E. \& Young, T. P. (2014). Native and domestic browsers and grazers reduce fuels, fire temperatures, and acacia ant mortality in an African savanna. Ecol. Appl. 24, 741-749.

Klop, E., van Goethem, J. \& de Iongh, H. H. (2007). Resource selection by grazing herbivores on post-fire regrowth in a West African woodland savanna. Wildl. Res. 34, 77-83 
Knight, E. H. \& Fox, B. J. (2000). Does habitat structure mediate the effects of forest fragmentation and human-induced disturbance on the abundance of Antechinus stuartii? Aust. J. Zool. 48, 577-595.

Koerner, S. E. \& Collins, S. L. (2014). Interactive effects of grazing, drought, and fire on grassland plant communities in North America and South Africa. Ecology 95, 98-109.

Kutt, A. S. \& Gordon, I. J. (2012). Variation in terrestrial mammal abundance on pastoral and conservation land tenures in north-eastern Australian tropical savannas. Anim. Conserv. $15,416-425$.

Kutt, A. S. \& Woinarski, J. C. Z. (2007). The effects of grazing and fire on vegetation and the vertebrate assemblage in a tropical savanna woodland in north-eastern Australia. $J$. Trop. Ecol. 23, 95-106.

Lagendijk, G., Page, B. R. \& Slotow, R. (2012). Short-term effects of single species browsing release by different-sized herbivores on sand forest vegetation community, South Africa. Biotropica 44, 63-72.

Law, B. S. \& Dickman, C. R. (1998). The use of habitat mosaics by terrestrial vertebrate fauna: implications for conservation and management. Biodiversity \& Conservation 7, 323-333.

Lazenby-Cohen, K. A. \& Cockburn, A. (1991). Social and foraging components of the home range in Antechinus stuartii (Dasyuridae: Marsupialia). Aust. J. Ecol. 16, 301-307.

Leigh, J., Wimbush, D., Wood, D., Holgate, M., Slee, A., Stanger, M. \& Forrester, R. (1987). Effects of rabbit grazing and fire on a sub-alpine environment .I. Herbaceous and shrubby vegetation. Aust. J. Bot. 35, 433-464. 
463 Lindenmayer, D. B., Likens, G. E., Krebs, C. J. \& Hobbs, R. J. (2010). Improved probability of detection of ecological "surprises". Proceedings of the National Academy of Sciences $107,21957-21962$.

Lindenmayer, D. B., MacGregor, C., Welsh, A., Donnelly, C., Crane, M., Michael, D.,

Pinheiro, J. \& Bates, D. (2000). Mixed-Effects Models in S and S-PLUS. New York, NY: Montague-Drake, R., Cunningham, R., Brown, D., Fortescue, M., Dexter, N., Hudson, M. \& Gill, A. M. (2008). Contrasting mammal responses to vegetation type and fire. Wildl. Res. 35, 395-408.

Meers, T. \& Adams, R. (2003). The impact of grazing by eastern grey kangaroos (Macropus giganteus) on vegetation recovery after fire at Reef Hills Regional Park, Victoria. Ecol. Manage. Restor. 4, 126-132.

Moreno, S. \& Villafuerte, R. (1995). Traditional management of scrubland for the conservation of rabbits Oryctolagus cuniculus and their predators in Doñana National Park, Spain. Biol. Conserv. 73, 81-85.

Morrison, D. A., Buckney, R. T., Bewick, B. J. \& Cary, G. J. (1996). Conservation conflicts over burning bush in south-eastern Australia. Biol. Conserv. 76, 167-175.

Noss, R. F., Franklin, J. F., Baker, W. L., Schoennagel, T. \& Moyle, P. B. (2006). Managing fire-prone forests in the western United States. Front. Ecol. Environ. 4, 481-487.

Pedersen, S., Andreassen, H. P., Keith, D. A., Skarpe, C., Dickman, C. R., Gordon, I. J., Crowther, M. S. \& McArthur, C. (2014). Relationships between native small mammals and native and introduced large herbivores. Austral Ecol. 39, 236-243.

Penn, A. M., Sherwin, W. B., Lunney, D. \& Banks, P. B. (2003). The effects of a lowintensity fire on small mammals and lizards in a logged, burnt forest. Wildl. Res. 30, 477-486. Springer-Verlag. 
R Core Team (2013). A language and environment for statistical computing. Vienna, Austria. URL http://www.R-project.org/: R Foundation for Statistical Computing.

Royo, A. A. \& Carson, W. P. (2006). On the formation of dense understory layers in forests worldwide: consequences and implications for forest dynamics, biodiversity, and succession. Can. J. For. Res. 36, 1345-1362.

Royo, A. A., Collins, R., Adams, M. B., Kirschbaum, C. \& Carson, W. P. (2010). Pervasive interactions between ungulate browsers and disturbance regimes promote temperate forest herbaceous diversity. Ecology 91, 93-105.

Shine, R. (1984). Reproductive biology and food habits of the Australian elapid snakes of the genus Cryptophis. J. Herpetol. 18, 33-39.

Sinclair, A. R. E. \& Byrom, A. E. (2006). Understanding ecosystem dynamics for conservation of biota. J. Anim. Ecol. 75, 64-79.

Smit, R., Bokdam, J., den Ouden, J., Olff, H., Schot-Opschoor, H. \& Schrijvers, M. (2001). Effects of introduction and exclusion of large herbivores on small rodent communities.

Stein, A., Gerstner, K. \& Kreft, H. (2014). Environmental heterogeneity as a universal driver of species richness across taxa, biomes and spatial scales. Ecol. Lett. 17, 866-880.

Stokes, V. L., Pech, R. P., Banks, P. B. \& Arthur, A. D. (2004). Foraging behaviour and habitat use by Antechinus flavipes and Sminthopsis murina (Marsupialia: Dasyuridae) in response to predation risk in eucalypt woodland. Biol. Conserv. 117, 331-342.

Taws, N. (1998). Fire and vegetation management in Jervis Bay Territory, Report. Canberra: Environment Australia. lizard communities in eastern Australian forests. Austral Ecol. 26, 193-204. 
512 Tolhurst, K. G. \& Turvey, N. D. (1992). Effects of bracken (Pteridium esculentum (forst. f.)

513 Cockayne) on eucalypt regeneration in west-central Victoria. For. Ecol. Manage. 54, $514 \quad 45-67$.

515 Tuft, K. D., Crowther, M. S. \& McArthur, C. (2012). Fire and grazing influence food 516 resources of an endangered rock-wallaby. Wildl. Res. 39, 436-445.

517 Tylianakis, J. M., Didham, R. K., Bascompte, J. \& Wardle, D. A. (2008). Global change and species interactions in terrestrial ecosystems. Ecol. Lett. 11, 1351-1363.

Van Langevelde, F., Van De Vijver, C. A. D. M., Kumar, L., Van De Koppel, J., De Ridder, N., Van Andel, J., Skidmore, A. K., Hearne, J. W., Stroosnijder, L., Bond, W. J., Prins, H. H. T. \& Rietkerk, M. (2003). Effects of fire and herbivory on the stability of savanna ecosystems. Ecology 84, 337-350.

Webb, J. K., Pringle, R. M., Shine, R. \& Lannoo, M. J. (2004). How do nocturnal snakes select diurnal retreat sites? Copeia 2004, 919-925.

Webb, J. K. \& Shine, R. (2008). Differential effects of an intense wildfire on survival of sympatric snakes. J. Wildl. Manage. 72, 1394-1398.

Webb, J. K., Shine, R., Pringle, R. M. \& Lannoo, M. J. (2005). Canopy removal restores habitat quality for an endangered snake in a fire suppressed landscape. Copeia 2005, 894-900.

While, G. M. \& McArthur, C. (2006). Distance from cover affects artificial food-patch depletion by macropod herbivores. Wildl. Res. 33, 565-570.

Willig, M. R. \& Walker, L. R. (1999). Disturbance in terrestrial ecosystems: Salient themes, synthesis, and future directions. In Ecosystems of the World 16: Ecosystems of Disturbed Ground: 747-768. Walker, L. R. (Ed.). Amsterdam: Elsevier Science.

Wisdom, M. J., Vavra, M., Boyd, J. M., Hemstrom, M. A., Ager, A. A. \& Johnson, B. K. (2006). Understanding ungulate herbivory-episodic disturbance effects on vegetation dynamics: Knowledge gaps and management needs. Wildl. Soc. Bull. 34, 283-292. 
538 Zuur, A. F., Ieno, E. N., Walker, N. J., Saveliev, A. A. \& Smith, G. M. (2009). Mixed effects models and extensions in ecology with R. New York, USA: Springer. 


\section{Tables}

542 Table 1. Predicted effects of fire and large herbivores on habitat and food resources for

543 vertebrates and the corresponding predicted responses of two small mammal and two reptile

544 species, based on their diet and habitat preferences. Habitat preferences are attributes which

545 have been associated with higher abundance in forest habitat for that species.

\begin{tabular}{|c|c|c|c|c|}
\hline \multirow{2}{*}{ Response group } & \multirow{2}{*}{ Habitat preference } & \multirow{2}{*}{ Diet } & \multicolumn{2}{|c|}{ Predicted response } \\
\hline & & & Fire & Herbivores \\
\hline \multicolumn{5}{|l|}{ Habitat and food resources } \\
\hline Understory cover & & & - & - \\
\hline Understory height & & & - & - \\
\hline Leaf litter depth & & & - & none \\
\hline Fresh plant growth & & & + & - \\
\hline Invertebrate prey & & & - & - \\
\hline $\begin{array}{l}\text { Vertebrates } \\
\text { European rabbit } \\
\text { (Oryctolagus cuniculus) }\end{array}$ & Open understory a & $\begin{array}{l}\text { Forbs and } \\
\text { grasses }^{b}\end{array}$ & + & - \\
\hline $\begin{array}{l}\text { Brown antechinus } \\
\text { (Antechinus stuartii) }\end{array}$ & $\begin{array}{l}\text { Dense, complex understory } a, c \\
\text { Tall understory }{ }^{\mathrm{a}} \\
\text { Abundant logs }^{d}\end{array}$ & Invertebrates ${ }^{c}$ & - & - \\
\hline $\begin{array}{l}\text { Delicate skink } \\
\text { (Lampropholis delicata) }\end{array}$ & $\begin{array}{l}\text { High canopy cover }{ }^{\mathrm{e}} \\
\text { Deep litter } \mathrm{f}, \mathrm{g} \\
\text { Tall understory } \mathrm{g}\end{array}$ & Invertebrates ${ }^{\mathrm{e}}$ & - & $?$ \\
\hline $\begin{array}{l}\text { Eastern small-eyed snake } \\
\text { (Cryptophis nigrescens) }\end{array}$ & Warm diurnal refuge ${ }^{h}$ & Skinks $^{h}$ & + & $?$ \\
\hline
\end{tabular}

${ }^{\mathrm{a} C}$ Catling and Burt (1995), ${ }^{\mathrm{b}}$ Davis, Coulson and Forsyth (2008), ${ }^{\mathrm{c}}$ Bennett (1993), ${ }^{\mathrm{d}}$ Knight and Fox (2000), ${ }^{\mathrm{e}}$ Bragg, Taylor and Fox (2005), ${ }^{\text {f }}$ Taylor and Fox (2001), ${ }^{g}$ Howard et al. (2003), , ' Webb et al. (2004),

546

547 
548 Table 2. Model rankings for linear mixed models (LMMs, vegetation) and generalised linear

549 mixed models (GLMMs, animals), testing the fixed effects of burning (B - burnt or unburnt),

550 exclosure (E - open, partial or full exclosure), time ( $\mathrm{T}$ - sampling event - categorical), and

551 their interactions on vegetation structure and animal occurrence. For brown antechinus, we

552 also ran model ranking on all subsets of a model with season ( $\mathrm{S}$ - autumn or spring)

553 substituted for time (i.e. $\mathrm{B}^{*} \mathrm{E}^{*} \mathrm{~S}$ ), to account for the strong seasonal variation in the

554 abundance of this species. $\mathrm{K}$ is the number of parameters estimated in the model, $\triangle \mathrm{AICc}$ is

555 the change in Aikaike's Information Criterion (corrected for small sample size) from the best-

556 ranked model. AICcWt is the Aikine Weight of the model, LL is the Log-likelihood.

\begin{tabular}{llrrrr}
\hline Data & Model terms & $\mathbf{K}$ & $\boldsymbol{\Delta}$ AlCc & AlCcWt & LL \\
\hline LMMs & & & & & \\
Understory cover & $\mathrm{B}+\mathrm{E}+\mathrm{T}+\mathrm{B}: \mathrm{T}+\mathrm{E}: \mathrm{T}+\mathrm{B}: \mathrm{E}+\mathrm{B}: \mathrm{E}: \mathrm{T}$ & 28 & 0 & 0.97 & -1454.7 \\
Cover excluding bracken & $\mathrm{B}+\mathrm{E}+\mathrm{T}+\mathrm{B}: \mathrm{T}+\mathrm{E}: \mathrm{T}$ & 20 & 0 & 0.74 & -1389.6 \\
Vegetation height & $\mathrm{B}+\mathrm{T}+\mathrm{B}: \mathrm{T}$ & 12 & 0 & 0.61 & 266.5 \\
& $\mathrm{~B}+\mathrm{E}+\mathrm{T}+\mathrm{B}: \mathrm{T}$ & 14 & 1.59 & 0.28 & 267.8 \\
Litter depth & $\mathrm{B}+\mathrm{T}+\mathrm{B}: \mathrm{T}$ & 12 & 0 & 0.82 & -429.5 \\
GLMMs & & & & & \\
Macropod scats & $\mathrm{B}+\mathrm{E}+\mathrm{T}$ & 15 & 0 & 0.6 & -500.6 \\
Rabbit diggings & $\mathrm{T}$ & 9 & 0 & 0.37 & -441.0 \\
& $\mathrm{E}+\mathrm{T}$ & 11 & 1.09 & 0.21 & -439.2 \\
& $\mathrm{~B}+\mathrm{T}$ & 10 & 1.64 & 0.16 & -440.7 \\
Brown antechinus & $\mathrm{E}+\mathrm{season}$ & 6 & 0 & 0.36 & -172.0 \\
& $\mathrm{~B}+\mathrm{E}+$ season & 7 & 1.4 & 0.18 & -171.5 \\
Delicate skink & $\mathrm{B}+\mathrm{E}+\mathrm{T}$ & 13 & 1.01 & 0.46 & -162.8 \\
& $\mathrm{~B}+\mathrm{T}$ & 11 & 1.35 & 0.39 & -165.3 \\
Eastern small-eyed snake & $\mathrm{B}$ & 4 & 0 & 0.67 & -60.4 \\
Beetles and spiders & $\mathrm{T}$ & 5 & 0 & 0.61 & -187.4 \\
& $\mathrm{~B}+\mathrm{T}$ & 6 & 1.85 & 0.24 & -187.0 \\
\hline
\end{tabular}

${ }^{a}$ Compares only partial-open months with open treatment (see methods) 


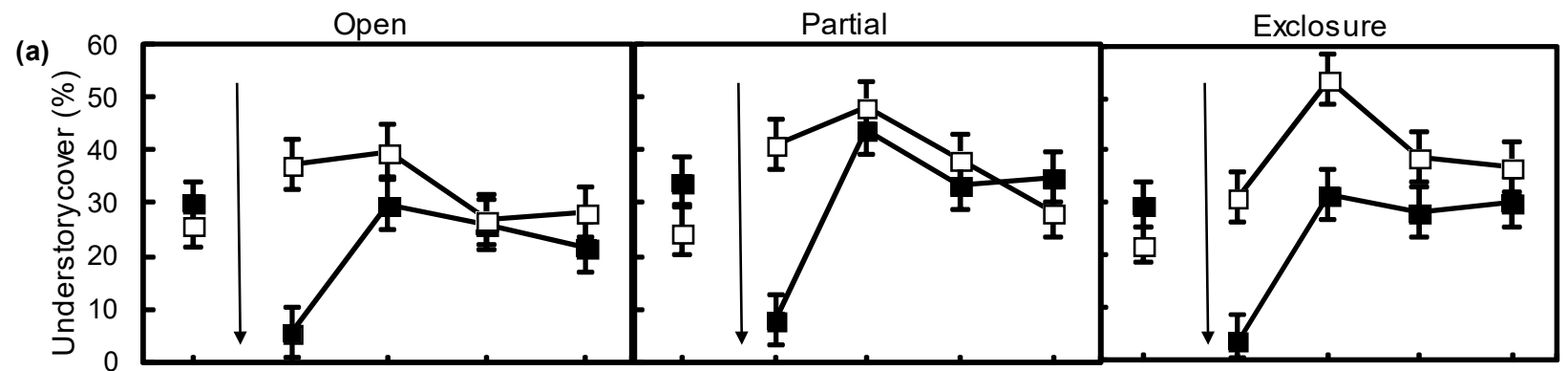

(b)

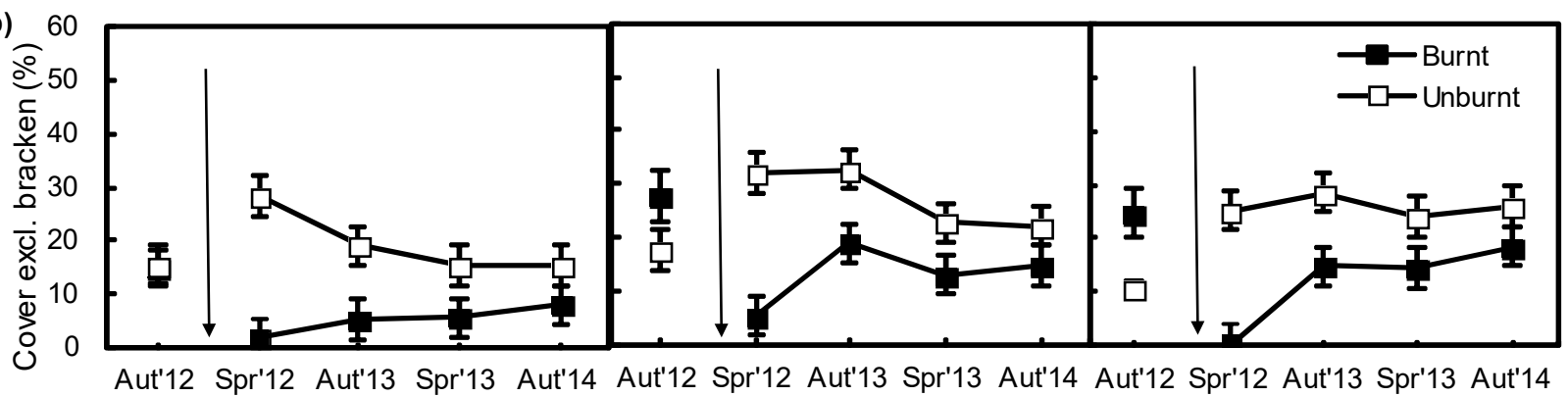

561 Figure 1. Vegetation structural responses to exclosure and burning treatments across

562 sampling periods, (a) total understory percent cover, and (b) understory percent cover,

563 excluding bracken (Pteridium esculentum). Values post-treatment are predicted means and

564 estimated SE from the top-ranked models. Pre-treatment data (May 2012) were not included

565 in the LMM, but are presented here (mean and SE) to allow comparison with post-treatment

566 data. Arrows indicate timing of prescribed burning. 


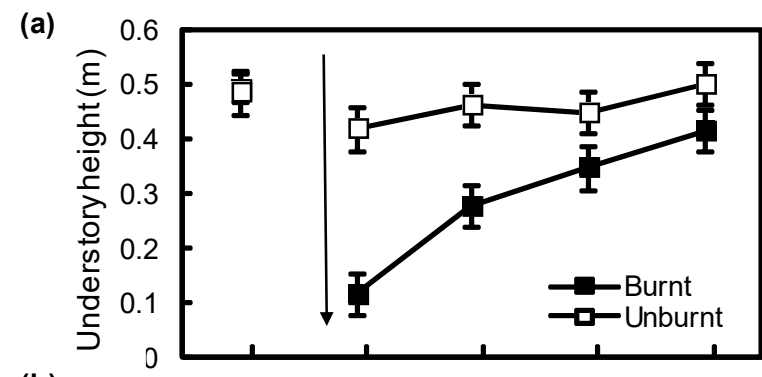

(b)

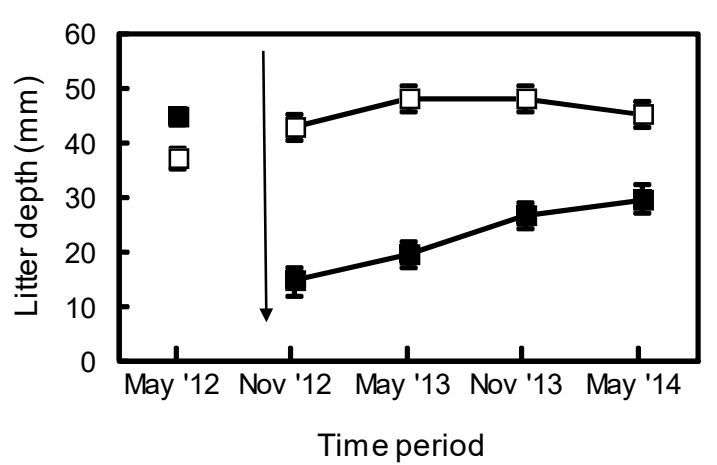

569 Figure 2. Response of understory height (a) and leaf litter depth (b) to burning treatment

570 across time periods. Values post-treatment are predicted means and SE from the top-ranked

571 models. Pre-treatment data (May 2012) were not included in the LMM, but are presented here

572 (mean and SE) to allow comparison with post-treatment data. Arrows indicate timing of

573 prescribed burning. 
(a)

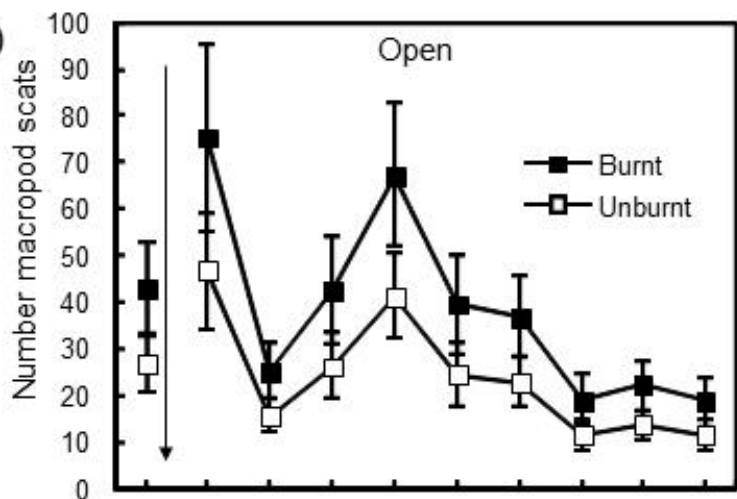

(b)

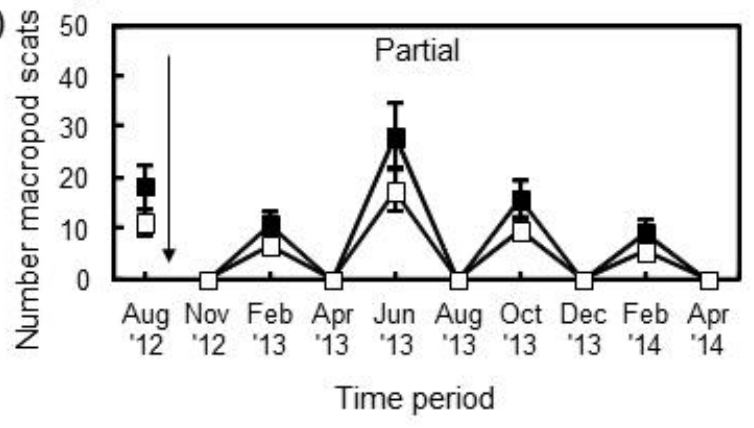

575 Figure 3. Number of macropod scats in burnt and unburnt sites through time in open (a) and

576 partial exclosure sites (b). Note that closed months of the partial exclosures (Nov 2012, Apr

5772013 etc.), and full exclosure sites were not included in the analysis as means for this group

578 were too low to allow model fit. Values for open sites and partial-open months are predicted

579 means and estimated SE from the top-ranked model. Arrows indicate timing of prescribed

580 burning (note Aug '12 counts were after implementation of herbivory treatments but before

581 burning treatment).

582 


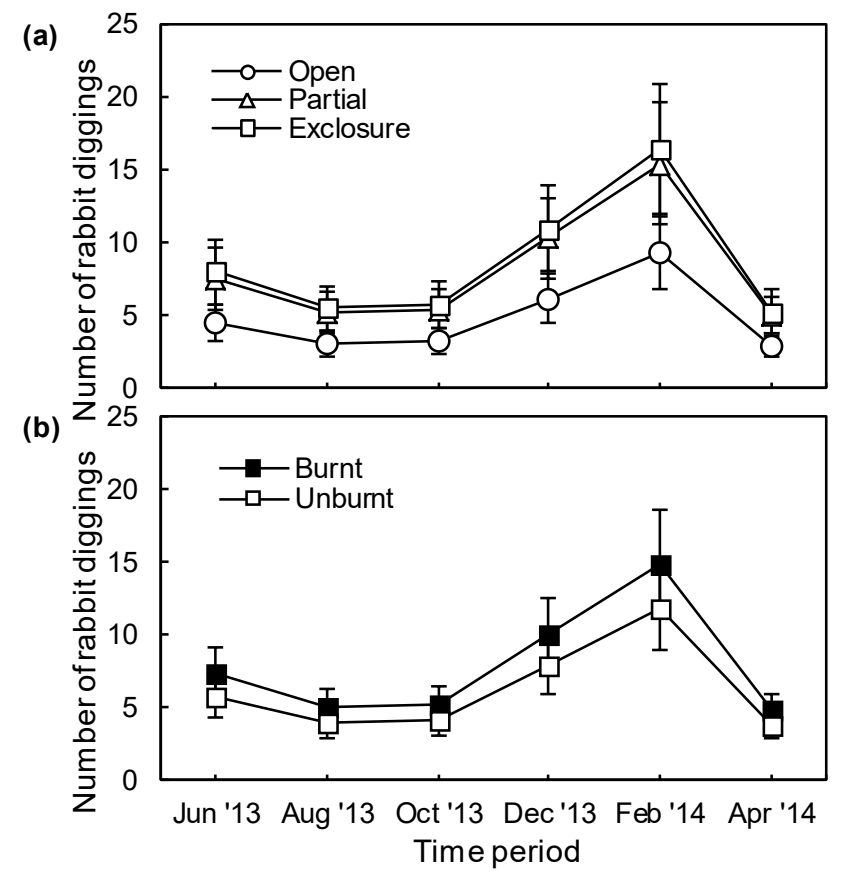

583

584 Figure 4. Number of rabbit (Oryctolagus cuniculus) diggings per site in the different

585 exclosure treatments (a) and burning treatments (b) over time. Values are predicted means

586 and estimated SE from the $2^{\text {nd }}$ (a) and $3^{\text {rd }}$ (b) ranked models respectively. The effect of time

587 alone (first-ranked model) can be clearly seen in both plots.

588 


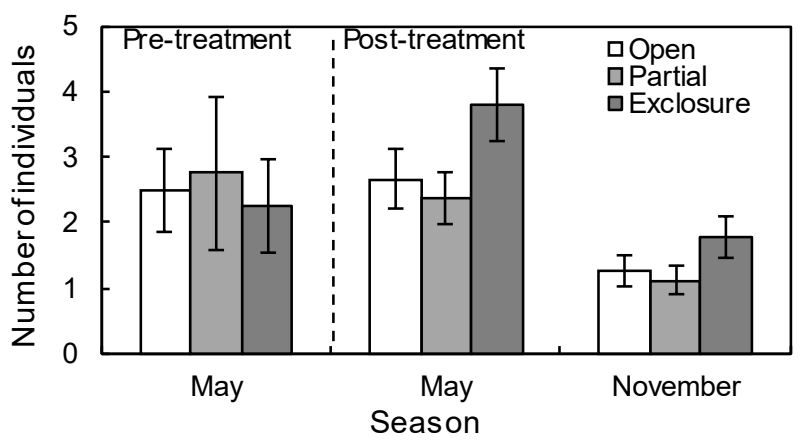

589

590 Figure 5. Number of individual brown antechinus (Antechinus stuartii) captured per site in

591 different seasons and herbivory treatments. Values post-treatment are predicted means and

592 SE from the top-ranked model based on two years of data (November 2012 to May 2014).

593 Pre-treatment data (May 2012) were not included in the GLMM, but are presented here

594 (mean and SE) to allow comparison with post-treatment data. 


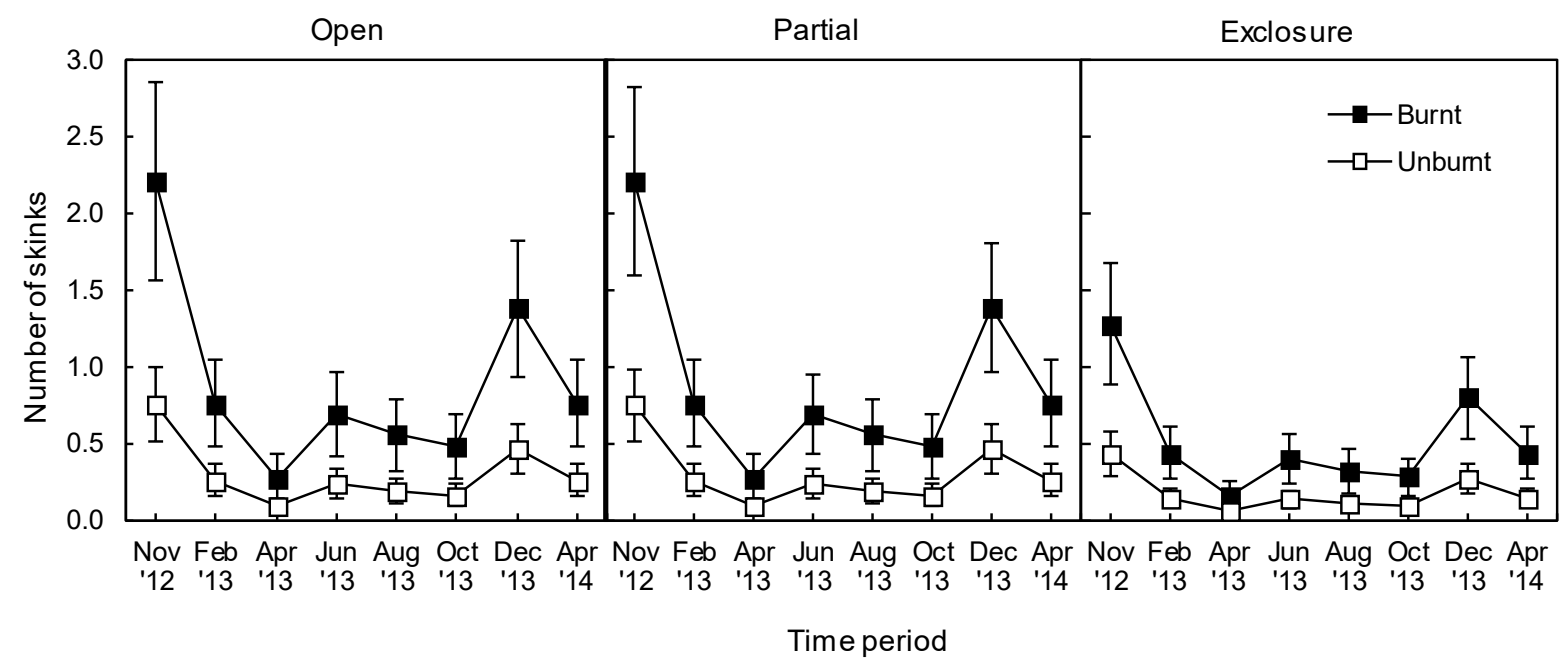

596 Figure 6. Number of delicate skinks (Lampropholis delicata) detected under artificial

597 substrates in the different burning and exclosure treatments across time. Values are predicted

598 means and SE from the top-ranked model. 